\title{
Electrospun PCL membranes incorporated with biosynthesized silver nanoparticles as antibacterial wound dressings
}

\author{
Robin Augustine $^{1} \cdot$ Nandakumar Kalarikkal $^{1,2} \cdot$ Sabu Thomas ${ }^{1,3}$
}

Received: 7 February 2015 / Accepted: 17 March 2015/Published online: 11 April 2015

(c) The Author(s) 2015. This article is published with open access at Springerlink.com

\begin{abstract}
An open wound is highly prone to bacterial colonization and infection. Bacterial barrier property is an important factor that determines the success of a wound coverage material. Apart from the bacterial barrier property, presence of antibacterial agents can successfully eliminate the invasion and colonization of pathogen in the wound. Silver nanoparticles are well-known antimicrobial agents against a wide range of microorganisms. Biosynthesized silver nanoparticles are more acceptable for medical applications due to superior biocompatibility than chemically synthesized ones. Presence of biomolecules on biosynthesized silver nanoparticles enhances its therapeutic efficiency. Polycaprolactone (PCL) is a well-known material for biomedical applications including wound dressings. Electrospinning is an excellent technique for the fabrication of thin membranes for wound coverage applications with barrier property against microbes. In this paper, we report the fabrication and characterization of electrospun PCL membranes incorporated with biosynthesized silver nanoparticles for wound dressing applications.
\end{abstract}

Robin Augustine

robin@ robinlab.in

Sabu Thomas

sabuchathukulam@yahoo.co.uk

1 International and Inter University Centre for Nanoscience and Nanotechnology, Mahatma Gandhi University, Kottayam 686560 , Kerala, India

2 School of Pure and Applied Physics, Mahatma Gandhi University, Kottayam 686 560, Kerala, India

3 School of Chemical Sciences, Mahatma Gandhi University, Kottayam 686 560, Kerala, India
Keywords Polycaprolactone - Silver nanoparticles · Biosynthesis · Wound dressings $\cdot$ Antibacterial

\section{Introduction}

Barrier property of materials to microbes is an important aspect in many biomedical applications like wound dressings and skin substitutes (Augustine et al. 2014a). Apart from the bacterial barrier property, presence of antibacterial agents can successfully eliminate invasion and colonization of pathogens in the wound (Augustine et al. 2014b). Wide range of biomaterials has been used by the medical practitioners to manage chronic wounds (Augustine et al. 2014c). The traditional forms of wound dressings are non-resorbable gauze and/or sponge, which are made of woven or non-woven cotton mesh, cellulose or cellulose derivatives (Augustine et al. 2014d). The traditional wound dressings sustained for over 40-45 years, which were then replaced by the advanced materials which comprise of thin films that are permeable to vapor and gases. Examples of such film wound dressings include alginates, polyurethane films and hydrogels (Augustine et al. 2013, 2014b, d).

Silver nanoparticles are well known as an antimicrobial agent against wide range of microorganisms (Ansari et al. 2014; Inbaneson et al. 2011; Augustine and Rajarathinam 2012). Biosynthesis of silver nanoparticles using plant resources is an eco-friendly, reliable approach and is suitable for large-scale production of nanoparticles (Vanaja and Annadurai 2013; Selvam and Sivakumar 2014). Since no chemical reagents are used in biosynthesis, it is environmentally safe and has potential for biological applications (Paul et al. 2015; Gaddala and Nataru 2015; Raju et al. 2014; Shanmugam et al. 2014; Kannan et al. 2013; 
Kandasamy et al. 2013). Biosynthesized nanoparticles are more acceptable in medical applications due to more biocompatibility than chemically synthesized ones (Sundaram et al. 2012). Previous reports suggested that the silver nanoparticles synthesized using medicinal plant extracts were capped by the organic components present in the plant extract (Maria et al. 2014; Sasikala et al. 2014). This will further enhance the therapeutic potential of these nanoparticles. Our previous report demonstrated that silver nanoparticles can successfully be synthesized in a facile and cost-effective way using leaf extracts of Piper nigrum (Augustine et al. 2014e). Biosynthesized silver nanoparticles were reported for their excellent antibacterial activity against wide range of microorganisms (Gnanadesigan et al. 2012; Kathiraven et al. 2014; Netala et al. 2014; Sinha et al. 2014; Kumar et al. 2015; Kokila et al. 2015; Roy et al. 2014). Antifungal activity of biosynthesized silver nanoparticles is also well studied (Kumar et al. 2013; Medda et al. 2014).

Poly( $\varepsilon$-caprolactone) (PCL) has got a lot of attention in biomedical applications due to its biocompatibility and biodegradability, and has been suggested for wide range of biomedical applications (Augustine et al. 2014a, b, f, g, h, 2015). Electrospinning has been emerged as a robust technology for the fabrication of non-woven, three-dimensional, porous, and nano or submicron scale fiberbased matrices. Electrospinning of PCL, its blends and composites has been tried for many applications including tissue engineering scaffolds and wound coverage materials (Augustine et al. 2014a, b, f, g, h, 2015). Madhavan et al. (2011) reported the fabrication of solvent-casted PCL scaffolds (films and conduits) containing chemically synthesized silver nanoparticles for vascular tissue engineering. They have demonstrated that these scaffolds were effective against both Gram-positive and Gram-negative bacteria without affecting endothelial cell proliferation. By combining the characteristic features of electrospun PCL membranes with antibacterial property of biosynthesized silver nanoparticles, provide a promising biomaterial for wound dressing applications.

In this paper, we report the fabrication and characterization of electrospun PCL membranes incorporated with biosynthesized silver nanoparticles for wound dressing applications. Silver nanoparticles were synthesized using black pepper leaf extract as reported in our previous study (Augustine et al. 2014e). Electrospun membranes of PCL containing biosynthesized silver nanoparticles were fabricated and characterized for the morphology, incorporation of silver nanoparticles in the PCL matrix and variation in tensile properties. Antibacterial activity of the fabricated PCL/silver nanocomposite membranes was also evaluated.

\section{Experimental}

\section{Materials used}

Silver nitrate was purchased from Loba chemie, India. Polycaprolactone (Mw 70,000) used in this study was purchased from Sigma-Aldrich, USA. Acetone was obtained from Merck, India. The $P$. nigrum leaves were freshly collected from the agricultural field near Kottayam, Kerala, India.

\section{Biosynthesis of silver nanoparticles}

About $10 \mathrm{~g}$ of freshly collected $P$. nigram leaves were grinded using mortar and pestle. $100 \mathrm{ml}$ of deionized water was added into the slurry and filtered through a cheese cloth. The filtrate was again filtered through Whatman No. 1 filter paper (pore size $25 \mu \mathrm{m}$ ). The fresh filtrate was centrifuged at 10,000 rpm for $15 \mathrm{~min}$ and the supernatant was used for the synthesis of nanoparticles.

Nanoparticle synthesis has been carried out based on our previous report (Augustine et al. 2014a). $2 \mathrm{mM}$ aqueous solution of silver nitrate $\left(\mathrm{AgNO}_{3}\right)$ was prepared in double distilled water and used for the synthesis of silver nanoparticles. $100 \mathrm{ml}$ aqueous solution of the silver nitrate was taken in a conical flask and heated to boiling with stirring using a magnetic stirrer. The flask was covered with aluminum foil to prevent light-mediated reduction of silver nitrate. Then, about $5 \mathrm{ml}$ of the $P$. nigram leaf extract was added drop wise into the silver nitrate solution. During this process, solution was mixed vigorously. The color change was evident (pale red) within 1 min after the addition of leaf extract. Then, the solution was removed from the stirrer and cooled to room temperature. A small portion of the obtained suspension was used for UVVisible spectroscopic analysis. Remaining part was centrifuged at 12,000 rpm several times in distilled water and finally in ethanol to get pure silver nanoparticles.

\section{Fabrication of PCL/silver nanocomposite membranes}

Electrospun membranes of PCL incorporated with biosynthesized silver nanoparticles were prepared by electrospinning $15 \mathrm{wt} \% \mathrm{PCL}$ in acetone. The electrospinning apparatus was assembled by Holmarc, India, and consisted of a syringe pump, a high-voltage power supply, and a $10-\mathrm{ml}$ syringe with an attached $21 \mathrm{G}$-diameter needle. The needle-to-collector distance was maintained at $15 \mathrm{~cm}$ with an applied voltage of $18 \mathrm{kV}$. The feeding rate of the solution was precisely controlled by a syringe pump system, which was adjusted to a flow rate of $1 \mathrm{ml} / \mathrm{h}$. As a 
collector, a thin aluminum sheet of $7 \mathrm{~cm}^{2}$ was attached to the fixed collector, which was grounded properly. 0.05, $0.25,0.5$ and $1 \mathrm{wt} \%$ of biosynthesized silver nanoparticles were accurately weighed and ultrasonicated for $15 \mathrm{~min}$ to properly disperse in acetone. Then, a known quantity of PCL was added to the above solution so that the final solution contains $15 \mathrm{wt} \% \mathrm{PCL}$, and the mixture was stirred with a magnetic stirrer for $12 \mathrm{~h}$ to ensure the dissolution of the pellets and proper mixing. About $10 \mathrm{ml}$ of the prepared solutions with various wt $\%$ of silver nanoparticles was taken in syringes and electrospun individually on aluminum sheets.

\section{Morphological characterization}

Morphological features of the fabricated neat PCL membranes and PCL/Ag nanocomposite membranes were observed using scanning electron microscope (SEM). The membranes were carefully sectioned with an approximate size of 3-mm length and $0.5-\mathrm{mm}$ width using a sharp scissor, and then mounted on SEM sample holder. Then, the samples were coated with platinum using a JEOL JFC 1600 Autofine coater. A JEOL JSM6390 scanning electron microscope at $30 \mathrm{kV}$ was used to analyze the samples. Images were taken in SE mode under high vacuum. The average fiber diameter of each sample was quantified from the SEM image using ImageJ software. Measurements were made at 100 random positions and the average of these measurements gave the diameter of the nanofibers.

\section{Energy dispersive X-ray (EDX) analysis}

The presence of biosynthesized silver nanoparticles in the polycaprolactone membrane was confirmed by EDX analysis using an Oxford Swift ED attached to JEOL JSM 6390 SEM, based on the energy and intensity distribution of X-ray signals generated by the electron beam striking the surface of the specimen. The EDX chamber was cooled by liquid nitrogen during the analysis.

\section{Mechanical measurements}

Tensile property of a wound dressing material should be comparable with that of human skin to avoid displacement of wound dressing and the pain during muscular movement. Tensile tests of the electrospun PCL and PCL/Ag nanocomposite membrane were carried out with a Tinus Olsen H50 KT Universal Testing Machine according to the ASTM D 882 standard by applying a 500-N load cell at a crosshead speed of $1 \mathrm{~mm} / \mathrm{min}$. All the samples were cut into rectangles with dimensions of $6 \times 1 \mathrm{~cm}^{2}$ and vertically mounted in between two mechanical gripping units of the tester, leaving a $3-\mathrm{cm}$ gauge length for mechanical loading. The sample thicknesses were measured with an electronic micrometer having a precision of $1 \mu \mathrm{m}$. The average values of tensile property were obtained from the results of five tests and expressed as the mean \pm standard deviation (SD).

\section{Antimicrobial activity}

In vitro antibacterial activity of the PCL/Ag nanocomposite membranes was evaluated by Kirby Bauer agar diffusion test. The bacterial strains Escherichia coli (ATCC 12228) and Staphylococcus aureus (ATCC6538-P) were used as representatives of Gram-negative and Grampositive bacteria, respectively. The bacteria were cultured in Mueller-Hinton Broth (MHB) at $37{ }^{\circ} \mathrm{C}$ and prepared to the turbidity equivalent to $0.5 \mathrm{McF}$ arland standards. Then, $100 \mu$ of the bacterial suspension was spread on the nutrient agar. The discs of electrospun PCL membranes with various concentrations of silver nanoparticles were cut into 6-mm-diameter circular pieces and placed on the surface of the inoculated Mueller-Hinton Agar (MHA) plates. A standard antibiotic disc was used as positive control (Ciprofloxacin, $30 \mu \mathrm{g} / \mathrm{disc}$ ). The culture plates were incubated for overnight in an incubator at $37{ }^{\circ} \mathrm{C}$. The diameters of the inhibition zones were measured in millimeters $(\mathrm{mm})$. The experiment was repeated for three times to get an average value and the results were expressed as mean $\pm \mathrm{SD}$.

\section{Results and discussion}

\section{Morphological characterization of PCL/Ag nanocomposite membranes}

Figure 1 shows SEM micrographs of the electrospun neat PCL membrane and PCL/Ag nanocomposite membranes. All the fabricated membranes showed uniform fiber diameter distribution without any beaded morphology. From the SEM images, it is evident that the fiber diameter decreased to a large extent while incorporating silver nanoparticles in the PCL matrix. The fiber diameters were calculated from the SEM micrographs and are shown in Fig. 2. Average fiber diameter of neat PCL membrane was $1672 \mathrm{~nm}$. In the case of PCL/Ag nanocomposites, as the nanoparticle concentration increased, the fiber diameter was reduced. Incorporation of $0.05 \mathrm{wt} \%$ silver nanoparticles resulted in the formation of fibers with average fiber diameter of $1465 \mathrm{~nm}$. Further addition of silver nanoparticles resulted in a considerable reduction in fiber diameter, and at $1 \mathrm{wt} \%$ silver nanoparticle concentration, the average fiber diameter was $834 \mathrm{~nm}$. Addition of silver nanoparticles resulted in the accumulation of a 
Fig. 1 SEM morphology of fabricated PCL membranes (a) and PCL/Ag nanocomposite membranes containing $0.05 \mathrm{wt} \%$ (b), $0.5 \mathrm{wt} \%$ (c) and $1 \mathrm{wt} \%$ (d) silver nanoparticles
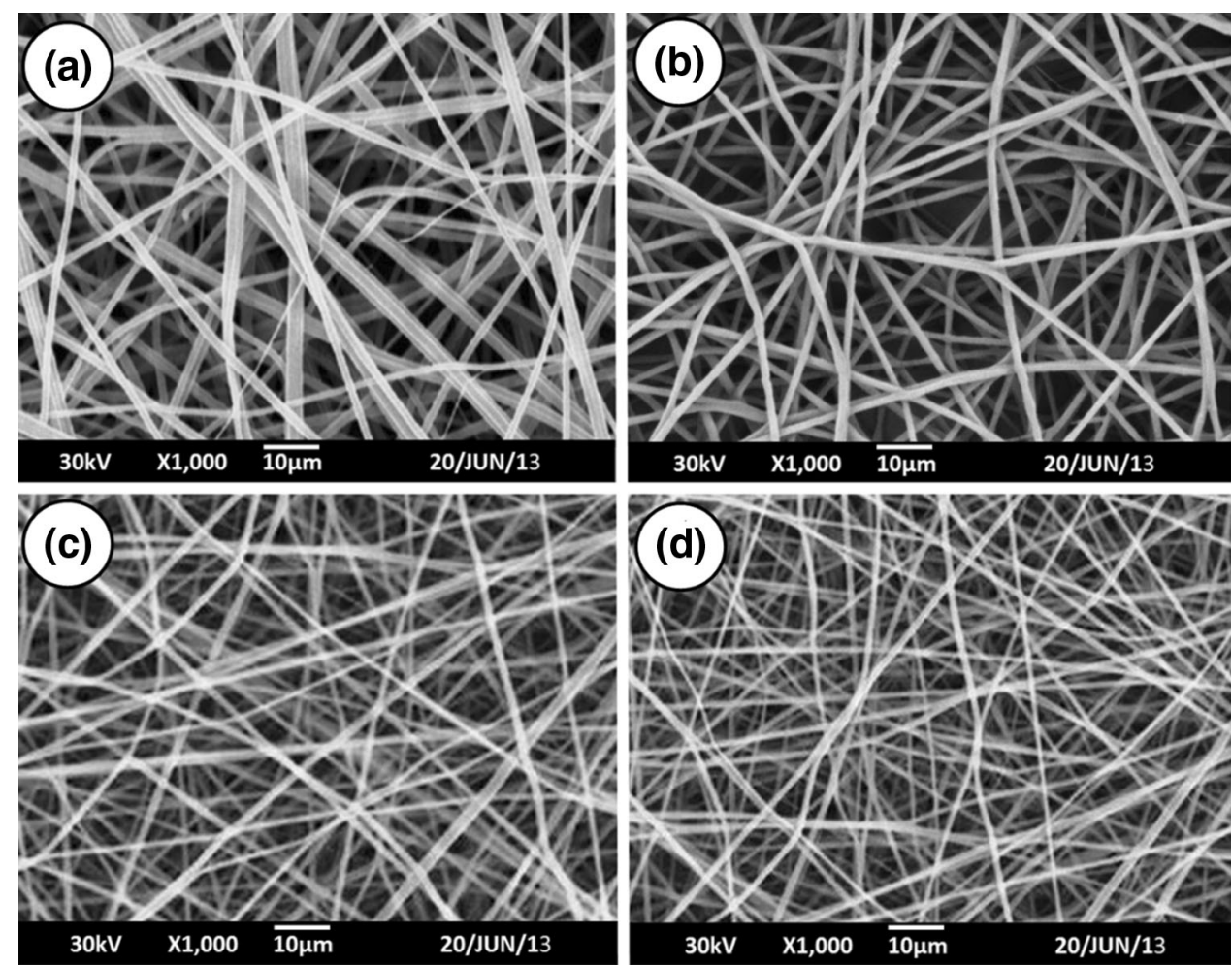

Fig. 2 Fiber diameter distribution of fabricated PCL membranes containing various concentrations of biosynthesized silver nanoparticles

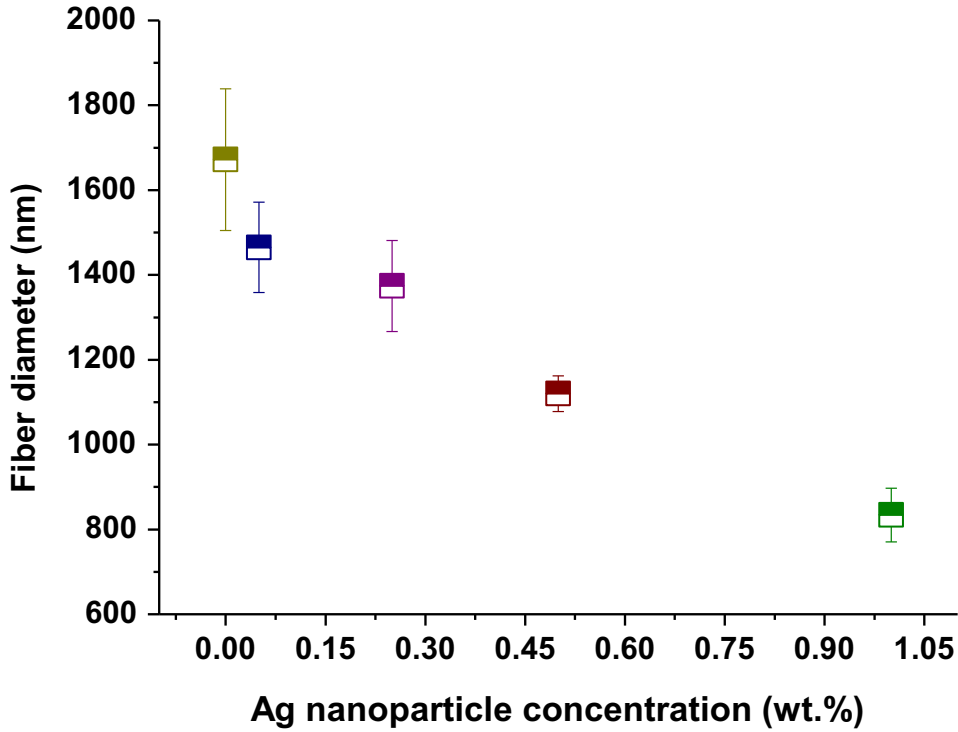

EDX analysis

The EDX spectrum of PCL and PCL/Ag nanocomposite membranes confirmed the presence of silver nanoparticles in the PCL membranes. It also confirmed that the silver nanoparticles have reached the collector along with the polymer solution during the electrospinning process. Spectra of neat PCL membrane and silver nanoparticleincorporated PCL membranes at various filler content are shown in Fig. 3. In the case of neat PCL membrane, there narrower (Augustine et al. 2014b).

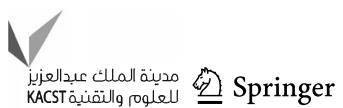




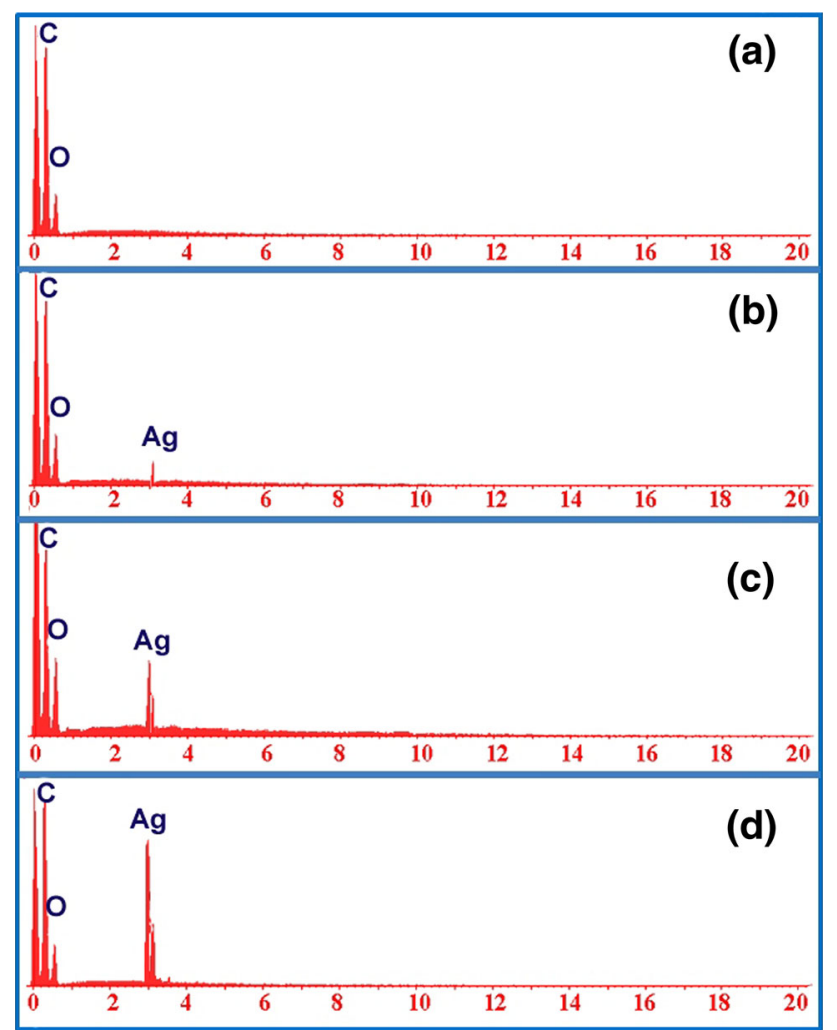

Fig. 3 Representative EDX spectrum of fabricated neat PCL membrane (a) and PCL/Ag nanocomposite membranes containing $0.05 \mathrm{wt} \%$ (b), $0.5 \mathrm{wt} \%$ (c) and $1 \mathrm{wt} \%$ (d) Ag nanoparticles

are some sharp, low-energy peaks that correspond to the elements carbon and oxygen (Fig. 3a), whereas, in the case of PCL/silver nanocomposite membranes, two additional peaks could be observed in the middle part of the spectrum between 2 and $4 \mathrm{keV}$. These maxima are related to silver $\mathrm{K}$ and $\mathrm{L}$ core levels. While incorporating $0.05 \mathrm{wt} \%$ silver nanoparticles, the peak intensities corresponding to silver were very low. However, in the case of PCL/Ag nanocomposite membranes containing 0.5 and $1 \mathrm{wt} \%$ silver nanoparticles, the peaks were well distinguishable (Fig. 3c, d).

\section{Tensile strength}

The typical tensile stress-strain curves for electrospun PCL/Ag nanocomposite membranes are presented in Fig. 4. From the figure, it is evident that by adding lower silver nanoparticle content, the tensile strength of the membranes increased with increasing nanoparticle content. The increase of the tensile modulus of the composite proceeds linearly with the silver nanoparticle content up to $0.5 \mathrm{wt} \%$, while further increase in the silver nanoparticle content led to a decrease in tensile strength and elongation at break of the PCL/Ag nanocomposite membranes. The smaller weight percentage of the silver nanoparticles

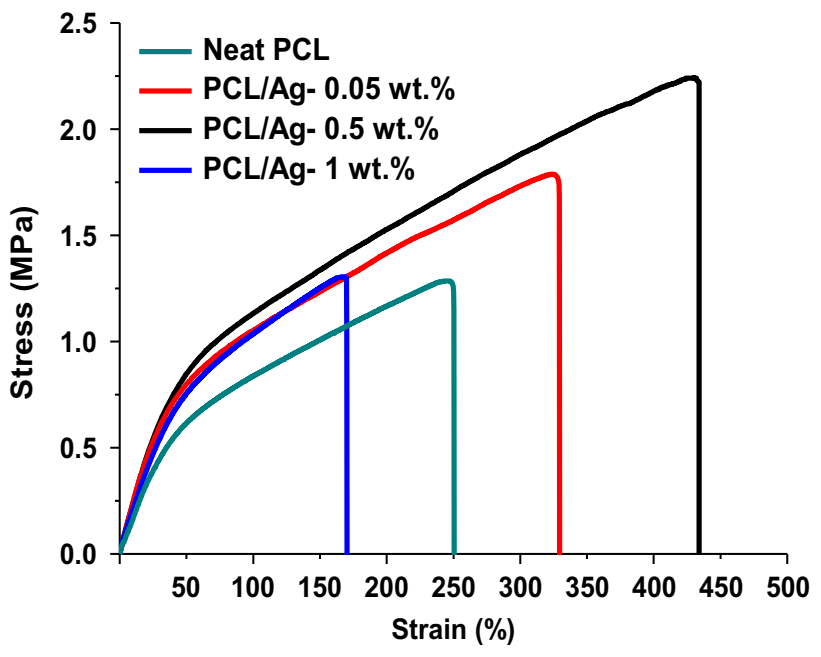

Fig. 4 Representative stress-strain curves of fabricated PCL/Ag nanocomposite membranes

resulted in a strong reinforcing effect, increasing the tensile modulus and inhibiting polymer drawing. The PCL membrane with $0.5 \mathrm{wt} \%$ silver nanoparticles showed superior tensile strength compared to neat PCL membrane. At higher silver nanoparticle content, the elasticity of the PCL membrane seemed to be decreased a large extent. This is due to the fact that nanoparticles have high surface energy and are easy to agglomerate, which leads to the poor dispersion of them in polymer matrix. Agglomerates of silver nanoparticles thus formed in the polymer matrix can act as stress concentration centers that prevent the stress transfer from the polymer matrix to the fillers. Whereas, at lower percentages of silver nanoparticle, there will be a uniform dispersion of silver nanoparticles in PCL polymer matrix, more uniform distribution of stress, minimized formation of stress concentration centers, increased interfacial area for stress transfer from the polymer matrix to the fillers, and good mechanical properties (Augustine et al. 2014b). From the tensile testing results (Table 1), it is clear that the overall tensile properties were much higher for $0.5 \mathrm{wt} \%$ silver nanoparticle-incorporated membranes. Maximum elongation (\%), modulus and break stress showed similar trends. Electrospun neat PCL membranes have shown an elongation at break of $250 \pm 8 \mathrm{MPa}$ which is an indication of high elasticity of the material. While incorporating biosynthesized silver nanoparticles, the elasticity has increased to $328 \pm 12 \mathrm{MPa}$. Tensile strength and modulus were also highest at this concentration. The incorporation of $1 \mathrm{wt} \%$ silver nanoparticles in PCL matrix increased the tensile strength of the nanocomposite, but decreased the tensile modulus and elongation at break compared to the neat PCL membrane. These results indicated that PCL/Ag nanocomposite membranes with lower silver nanoparticle content would produce fibers with better mechanical 
Table 1 Tensile properties of electrospun PCL membranes incorporated with various concentrations of silver nanoparticles

\begin{tabular}{llll}
\hline Sample & $\begin{array}{l}\text { Stress at } \\
\text { break (MPa) }\end{array}$ & $\begin{array}{l}\text { Elongation at } \\
\text { break (\%) }\end{array}$ & $\begin{array}{l}\text { Modulus } \\
(\mathrm{MPa})\end{array}$ \\
\hline Neat PCL & $1.24 \pm 0.21$ & $250 \pm 8$ & $2.84 \pm 0.87$ \\
PCL/Ag 0.05 wt\% & $1.72 \pm 0.17$ & $328 \pm 12$ & $3.38 \pm 0.74$ \\
PCL/Ag 0.5 wt\% & $2.78 \pm 0.18$ & $427 \pm 16$ & $4.28 \pm 1.28$ \\
PCL/Ag 1 wt\% & $1.23 \pm 0.08$ & $251 \pm 11$ & $2.97 \pm 0.59$ \\
\hline
\end{tabular}
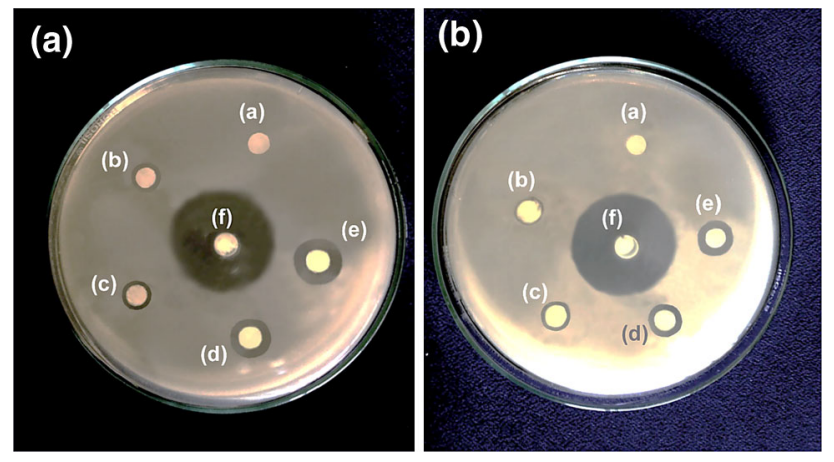

Fig. 5 Plates showing the antibacterial property of fabricated neat PCL membranes $(a)$, PCL/Ag nanocomposite membranes containing $0.05 \mathrm{wt} \%(b), 0.25 \mathrm{wt} \%(c), 0.5 \mathrm{wt} \%(d)$ and $1 \mathrm{wt} \%(e)$ silver nanoparticles on Staphylococcus aureus (a) and Escherichia coli (b)

properties. A wound dressing material should have adequate tensile strength, flexibility and elasticity. It is essential to have enough stress-bearing capacity and elasticity to keep the wound coverage material in the wound and to avoid the failure due to muscular movements (Johnson et al. 2009). The results of tensile properties of the electrospun PCL/Ag nanocomposite membranes were comparable with other reported values (Augustine et al. 2014h; Johnson et al. 2009). Daly and Odland (1979) reported comparable tensile properties for the human skin with that of the electrospun PCL membranes which are reported in the present study.

\section{Antibacterial property}

The antibacterial activity of the silver nanoparticle-incorporated PCL membranes was evaluated by observing their inhibitory activity (based on the disc diffusion method) against both Gram-positive (S. aureus) and Gram-negative (E. coli) bacteria. The results of the antimicrobial testing are shown in Fig. 5 and Table 2. From the figure, it is evident that the fabricated membrane containing silver nanoparticles had good antibacterial activity against both $S$. aureus and E. coli. According to the results obtained, neat PCL membranes have shown no activity against the tested bacteria. PCL membrane containing $0.05 \mathrm{wt} \%$ silver nanoparticles showed statistically significant antibacterial
Table 2 Diameter of inhibitory zone by disc diffusion technique using PCL/Ag nanocomposite membranes on S. aureus and E. coli

\begin{tabular}{lcr}
\hline Sample & \multicolumn{2}{l}{ Inhibitory zone $(\mathrm{mm})$} \\
\cline { 2 - 3 } & \multicolumn{1}{l}{ S aureus } & \multicolumn{1}{c}{ E coli } \\
\hline Neat PCL & $6.0 \pm 0.0$ & $6.0 \pm 0.0$ \\
PCL/Ag 0.05 wt\% & $7.4 \pm 0.3$ & $6.2 \pm 0.4$ \\
PCL/Ag 0.25 wt\% & $7.6 \pm 0.5$ & $7.1 \pm 0.3$ \\
PCL/Ag 0.5 wt\% & $9.5 \pm 0.6$ & $7.4 \pm 0.7$ \\
PCL/Ag 1 wt\% & $11.6 \pm 0.5$ & $7.9 \pm 0.6$ \\
Ciprofloxacin & $22.9 \pm 1.2$ & $21.6 \pm 0.8$ \\
\hline
\end{tabular}

activity with an inhibitory zone diameter of $7.4 \pm 0.3$ $(P=0.0061)$ and $6.2 \pm 0.4(P=0.0375)$ against $S$. aureus and E. coli, respectively. The PCL membrane containing $0.25 \mathrm{wt} \%$ silver nanoparticles showed an inhibitory zone diameter of $7.6 \pm 0.5(P=0.0081)$ and $7.1 \pm 0.3$ $(P=0.0087)$ against $S$. aureus and $E$. coli, respectively. Similarly, PCL membrane containing $0.5 \mathrm{wt} \%$ silver nanoparticles showed an inhibitory zone diameter of $9.5 \pm 0.6 \quad(P=0.0054) \quad$ and $7.4 \pm 0.7 \quad(P=0.0065)$ against $S$. aureus and E. coli, respectively. PCL membrane containing $1 \mathrm{wt} \%$ silver nanoparticles showed an inhibitory zone diameter of $11.6 \pm 0.5(P=0.0044)$ and $7.9 \pm 0.6$ $(P=0.0072)$ against $S$. aureus and $E$. coli, respectively. Antibacterial activity of the PCL/Ag nanocomposite membranes was higher against $S$. aureus than against $E$. coli. The reason for such an observation could be explained in terms of the difference in the cell wall structure of these bacteria. The outer cell membrane of Gramnegative bacteria contains lipopolysaccharide in its outer leaflet and phospholipids in the inner leaflet. But Grampositive bacteria lack such a lipopolysaccharide layer. All the PCL/Ag nanocomposite membranes have shown more antibacterial activity against $S$. aureus than $E$. coli as reported by other workers (Shrivastava et al. 2007), probably due to the difference in cell walls between Gram-positive and Gram-negative bacteria. Moreover, the presence of biosynthesized nanoparticles enhances the therapeutic efficacy of PCL/Ag nanocomposite membranes due to the antibacterial property of $P$. nigram. Antibacterial activity of black pepper (P. nigrum Linn.) and its mode of action on both Gram-negative and Gram-positive bacteria were already reported (Karsha and Lakshmi 2010). Based on the results obtained from the disc diffusion technique, it is clear that the fabricated PCL/Ag nanocomposite membranes can successfully inhibit bacterial colonization in wounds.

Since, the PCL/Ag nanocomposite membranes showed uniform fiber diameter distribution, good mechanical stability and excellent antibacterial activity, they can be used for wound dressing applications. However, in vitro and 
in vivo biocompatibility studies, wound healing evaluation, etc., should be carried out to address the safety issues of the fabricated material.

\section{Conclusion}

In this study, electrospun polycaprolactone membranes incorporated with various concentrations of biosynthesized silver nanoparticles were successfully fabricated and characterized. As the concentration of silver nanoparticles increased from 0.05 to $1 \mathrm{wt} \%$, fiber diameter was varied to a large extent. EDX analysis confirmed the successful incorporation of silver nanoparticles into the PCL matrix. Tensile strength, elongation at break and tensile modulus were much higher for PCL/Ag nanocomposite membranes up to $0.5 \mathrm{wt} \%$ of silver nanoparticle content. The inherent elastic nature of the PCL changed to a brittle nature after the incorporation of $1 \mathrm{wt} \%$ silver nanoparticles. The fabricated material showed excellent antibacterial activity against both $S$. aureus and $E$. coli, which suggests the ability of the fabricated material to prevent bacterial colonization in wounds covered with this material.

Acknowledgments The authors acknowledge Department of Biotechnology (DBT), Government of India, New Delhi for the financial support through MSUB IPLSARE program.

Open Access This article is distributed under the terms of the Creative Commons Attribution 4.0 International License (http://creativecommons.org/licenses/by/4.0/), which permits unrestricted use, distribution, and reproduction in any medium, provided you give appropriate credit to the original author(s) and the source, provide a link to the Creative Commons license, and indicate if changes were made.

\section{References}

Ansari MA, Khan HM, Khan AA, Cameotra SS, Pal R (2014) Antibiofilm efficacy of silver nanoparticles against biofilm of extended spectrum $\beta$-lactamase isolates of Escherichia coli and Klebsiella pneumoniae. Appl Nanosci 4(7):859-868

Augustine R, Rajarathinam K (2012) Synthesis and characterization of silver nanoparticles and its immobilization on alginate coated sutures for the prevention of surgical wound infections and the in vitro release studies. Int J Nano Dimens 2(3):205-212

Augustine R, Rajendran R, Cvelbar U, Mozetič M, George A (2013) Biopolymers for health, food, and cosmetic applications. Handb Biopolym Mater Blends Compos Gels Complex Netw 801-849

Augustine R, Dominic EA, Reju I, Kaimal B, Kalarikkal N, Thomas S (2014a) Electrospun polycaprolactone membranes incorporated with $\mathrm{ZnO}$ nanoparticles as skin substitutes with enhanced fibroblast proliferation and wound healing. RSC Adv 4(47):24777-24785

Augustine R, Kalarikkal N, Thomas S (2014a) An in vitro method for the determination of microbial barrier property (MBP) of porous polymeric membranes for skin substitute and wound dressing applications. Tissue Eng Regen Med 12(1):12-19
Augustine R, Dominic EA, Reju I, Kaimal B, Kalarikkal N, Thomas S (2014b) Investigation of angiogenesis and its mechanism using zinc oxide nanoparticle-loaded electrospun tissue engineering scaffolds. RSC Adv 4(93):51528-51536

Augustine R, Kalarikkal N, Thomas S (2014c) Role of wound dressings in the management of chronic and acute diabetic wounds. Diabetes Mellit Hum Health Care Holist Approach Diagn Treat 273-314

Augustine R, Kalarikkal N, Thomas S (2014c) Advancement of wound care from grafts to bioengineered smart skin substitutes. Prog Biomater 3(2-4):103-113

Augustine R, Kalarikkal N, Thomas S (2014d) A facile and rapid method for the black pepper leaf mediated green synthesis of silver nanoparticles and the antimicrobial study. Appl Nanosci 4(7):809-818

Augustine R, Malik HN, Singhal DK, Mukherjee A, Malakar D, Kalarikkal N, Thomas S (2014e) Electrospun polycaprolactone/ $\mathrm{ZnO}$ nanocomposite membranes as biomaterials with antibacterial and cell adhesion properties. J Polym Res 21(3):1-17

Augustine R, Dominic EA, Reju I, Kaimal B, Kalarikkal N, Thomas S (2014f) Electrospun poly ( $\varepsilon$-caprolactone)-based skin substitutes: in vivo evaluation of wound healing and the mechanism of cell proliferation. J Biomed Mater Res Part B Appl Biomater. doi:10. 1002/jbm.b.33325

Augustine R, Saha A, Jayachandran VP, Thomas S, Kalarikkal N (2015) Dose dependent effects of gamma irradiation on the materials properties and cell proliferation of electrospun polycaprolactone tissue engineering scaffolds. Int J Polym Mater Polym Biomater 64(10):526-533

Daly CH, Odland GF (1979) Age-related changes in the mechanical properties of human skin. J Investig Dermatol 73(1):84-87

Gaddala B, Nataru S (2015) Synthesis, characterization and evaluation of silver nanoparticles through leaves of Abrus precatorius L.: an important medicinal plant. Appl Nanosci 5(1):99-104

Gnanadesigan M, Anand M, Ravikumar S, Maruthupandy M, Ali MS, Vijayakumar V, Kumaraguru AK (2012) Antibacterial potential of biosynthesised silver nanoparticles using Avicennia marina mangrove plant. Appl Nanosci 2(2):143-147

Inbaneson SJ, Ravikumar S, Manikandan N (2011) Antibacterial potential of silver nanoparticles against isolated urinary tract infectious bacterial pathogens. Appl Nanosci 1(4):231-236

Johnson J, Niehaus A, Nichols S, Lee D, Koepsel J, Anderson D, Lannutti J (2009) Electrospun PCL in vitro: a microstructural basis for mechanical property changes. J Biomater Sci Polym Ed 20(4):467-481

Kandasamy K, Alikunhi NM, Manickaswami G, Nabikhan A, Ayyavu G (2013) Synthesis of silver nanoparticles by coastal plant Prosopis chilensis (L.) and their efficacy in controlling vibriosis in shrimp Penaeus monodon. Appl Nanosci 3(1):65-73

Kannan RRR, Arumugam R, Ramya D, Manivannan K, Anantharaman $P$ (2013) Green synthesis of silver nanoparticles using marine macroalga Chaetomorpha linum. Appl Nanosci 3(3):229-233

Karsha PV, Lakshmi OB (2010) Antibacterial activity of black pepper (Piper nigrum Linn.) with special reference to its mode of action on bacteria. Indian J Nat Prod Resour 1(2):213-215

Kathiraven T, Sundaramanickam A, Shanmugam N, Balasubramanian $\mathrm{T}$ (2014) Green synthesis of silver nanoparticles using marine algae Caulerpa racemosa and their antibacterial activity against some human pathogens. Appl Nanosci 5(4):499-504

Kokila T, Ramesh PS, Geetha D (2015) Biosynthesis of silver nanoparticles from Cavendish banana peel extract and its antibacterial and free radical scavenging assay: a novel biological approach. Appl Nanosci. doi:10.1007/s13204-0150401-2

Kumar P, Selvi SS, Govindaraju M (2013) Seaweed-mediated biosynthesis of silver nanoparticles using Gracilaria corticata

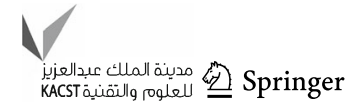


for its antifungal activity against Candida spp. Appl Nanosci 3(6):495-500

Kumar PS, Balachandran C, Duraipandiyan V, Ramasamy D, Ignacimuthu S, Al-Dhabi NA (2015) Extracellular biosynthesis of silver nanoparticle using Streptomyces sp. 09 PBT 005 and its antibacterial and cytotoxic properties. Appl Nanosci 5(2):169-180

Madhavan RV, Rosemary MJ, Nandkumar MA, Krishnan KV, Krishnan LK (2011) Silver nanoparticle impregnated poly $(\varepsilon-$ caprolactone) scaffolds: optimization of antimicrobial and noncytotoxic concentrations. Tissue Eng Part A 17(3-4):439-449

Maria BS, Devadiga A, Kodialbail VS, Saidutta MB (2014) Synthesis of silver nanoparticles using medicinal Zizyphus xylopyrus bark extract. Appl Nanosci. doi:10.1007/s13204-014-0372-8

Medda S, Hajra A, Dey U, Bose P, Mondal NK (2014) Biosynthesis of silver nanoparticles from Aloe vera leaf extract and antifungal activity against Rhizopus sp. and Aspergillus sp. Appl Nanosci. doi:10.1007/s13204-014-0387-1

Netala VR, Kotakadi VS, Nagam V, Bobbu P, Ghosh SB, Tartte V (2014) First report of biomimetic synthesis of silver nanoparticles using aqueous callus extract of Centella asiatica and their antimicrobial activity. Appl Nanosci. doi:10.1007/s13204-0140374-6

Paul JAJ, Selvi BK, Karmegam N (2015). Biosynthesis of silver nanoparticles from Premna serratifolia L. leaf and its anticancer activity in CCl4-induced hepato-cancerous Swiss albino mice. Appl Nanosci. doi:10.1007/s13204-014-0397-z

Sasikala A, Rao ML, Savithramma N, Prasad, TNVKV (2014) Synthesis of silver nanoparticles from stem bark of Cochlospermum religiosum (L.) Alston: an important medicinal plant and evaluation of their antimicrobial efficacy. Appl Nanosci. doi:10. 1007/s13204-014-0380-8
Raju, D., Paneliya, N., Mehta, U. J (2014) Extracellular synthesis of silver nanoparticles using living peanut seedling. Appl Nanosci 4(7):875-879

Roy K, Sarkar CK, Ghosh CK (2014) Plant-mediated synthesis of silver nanoparticles using parsley (Petroselinum crispum) leaf extract: spectral analysis of the particles and antibacterial study. Appl Nanosci. doi:10.1007/s13204-014-0393-3

Selvam GG, Sivakumar K (2014) Phycosynthesis of silver nanoparticles and photocatalytic degradation of methyl orange dye using silver (Ag) nanoparticles synthesized from Hypnea musciformis (Wulfen) JV Lamouroux. Appl Nanosci. doi:10.1007/s13204014-0356-8

Shanmugam N, Rajkamal P, Cholan S, Kannadasan N, Sathishkumar K, Viruthagiri G, Sundaramanickam A (2014) Biosynthesis of silver nanoparticles from the marine seaweed Sargassum wightii and their antibacterial activity against some human pathogens. Appl Nanosci 4(7):881-888

Shrivastava S, Bera T, Roy A, Singh G, Ramachandrarao P, Dash D (2007) Characterization of enhanced antibacterial effects of novel silver nanoparticles. Nanotechnology 18(22):225103

Sinha SN, Paul D, Halder N, Sengupta D, Patra SK (2014) Green synthesis of silver nanoparticles using fresh water green alga Pithophora oedogonia (Mont.) Wittrock and evaluation of their antibacterial activity. Appl Nanosci. doi:10.1007/s13204-0140366-6

Sundaram PA, Augustine R, Kannan M (2012) Extracellular biosynthesis of iron oxide nanoparticles by Bacillus subtilis strains isolated from rhizosphere soil. Biotechnol Bioprocess Eng 17(4):835-840

Vanaja M, Annadurai G (2013) Coleus aromaticus leaf extract mediated synthesis of silver nanoparticles and its bactericidal activity. Appl Nanosci 3(3):217-223 